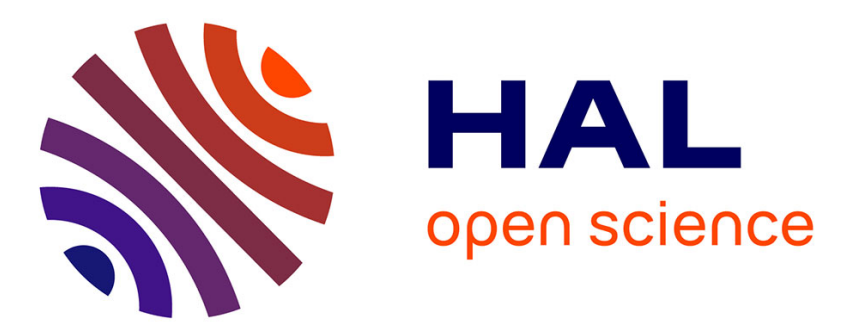

\title{
Highly Promoted Photocatalytic Hydrogen Generation by Multiple Electron Transfer Pathways
}

Xiaojiao Yuan, Cong Wang, Diana Dragoe, Patricia Beaunier, Christophe Colbeau-Justin, Hynd Remita

\section{To cite this version:}

Xiaojiao Yuan, Cong Wang, Diana Dragoe, Patricia Beaunier, Christophe Colbeau-Justin, et al.. Highly Promoted Photocatalytic Hydrogen Generation by Multiple Electron Transfer Pathways. Applied Catalysis B: Environmental, 2021, 281, pp.119457. 10.1016/j.apcatb.2020.119457 . hal03092690

\section{HAL Id: hal-03092690 \\ https://hal.science/hal-03092690}

Submitted on 23 Nov 2021

HAL is a multi-disciplinary open access archive for the deposit and dissemination of scientific research documents, whether they are published or not. The documents may come from teaching and research institutions in France or abroad, or from public or private research centers.
L'archive ouverte pluridisciplinaire HAL, est destinée au dépôt et à la diffusion de documents scientifiques de niveau recherche, publiés ou non, émanant des établissements d'enseignement et de recherche français ou étrangers, des laboratoires publics ou privés. 


\title{
Highly Promoted Photocatalytic Hydrogen Generation by Efficient Multiple Electron Transfer Pathways
}

Xiaojiao Yuan ${ }^{1}$, Cong Wang ${ }^{1}$, Diana Dragoe ${ }^{2}$, Patricia Beaunier ${ }^{3}$, Christophe Colbeau-Justin ${ }^{1}$, Hynd Remita ${ }^{1,4^{*}}$

\footnotetext{
${ }^{1}$ Institut de Chimie Physique, UMR 8000 CNRS, Université Paris-Saclay, 91405 Orsay, France

${ }^{2}$ Institut de Chimie Moléculaire et des Matériaux d’Orsay, Université Paris-Saclay, 91405 Orsay, France

${ }^{3}$ Sorbonne Université, CNRS, UMR 7197, Laboratoire de Réactivité de Surface, 75005 Paris, France

${ }^{4}$ CNRS, Institut de Chimie Physique, UMR 8000, 91405 Orsay, France

E-mail : hynd.remita@universite-paris-saclay.fr
}

\begin{abstract}
A facile development of highly efficient photocatalytic nanostructures for solar fuel production via controlled cocatalyst deposition is described. $2 \mathrm{~nm}$-Pt nanoparticles were selectively synthesized by radiolysis on polypyrrole $(\mathrm{PPy}), \mathrm{TiO}_{2}$ or on both $\mathrm{PPy}-\mathrm{TiO}_{2}$ (noted respectively $(\mathrm{Pt}-\mathrm{PPy})-\mathrm{TiO} 2,(\mathrm{Pt}-$ $\left.\mathrm{TiO}_{2}\right)-\mathrm{PPy}$ and $\left.\mathrm{Pt}-\left(\mathrm{PPy}-\mathrm{TiO}_{2}\right)\right)$. The PPy nanostructures not only act a photosensitizer, but also as a connection bridge between two light-harvesting semiconductors to form a $\mathrm{p}-\mathrm{n}$ heterojunction, which absorbs UV and visible light efficiently. The designed heterojunction photocatalyst nanostructures (Pt$\left.\left(\mathrm{PPy}-\mathrm{TiO}_{2}\right)\right)$ exhibit broadened absorption to the visible region, long life-time of charge carriers and high photocatalytic activity for hydrogen production. This activity is markedly enhanced compared with that of (Pt-PPy)-TiO 2 and $\left(\mathrm{Pt}-\mathrm{TiO}_{2}\right)-\mathrm{PPy}$, and is ascribed to more efficient multiple electron transfer pathways. Such designed structures provide promising ways for selected site deposition of
\end{abstract}


metal nanoparticles on heterojunction semiconductors in high efficiency conversion from solar energy to solar fuel application.

Keywords: Heterojunction photocatalyst, Hydrogen generation, Polypyrrole, $\mathrm{TiO}_{2}$, Platinum cocatalyst.

\section{Introduction}

Hydrogen $\left(\mathrm{H}_{2}\right)$ is a considerable green and renewable energy. A lot of attention is presently paid to develop photo- or electro-catalysts to solve environmental issues and to produce solar hydrogen because of its high-energy capacity and environmental friendliness [1]. The photocatalytic hydrogen generation from water splitting with semiconductors under solar irradiation is a promising way to produce hydrogen, which has attracted many researchers to extensively investigate and develop appropriate semiconductor photocatalysts to increase their photocatalytic activity [2-7]. The enhancement of photocatalytic performance is generally owing to a fast transfer of photogenerated electrons from the semiconductor to metal leading to the longer lifetime of the excited charge carriers [8]. Besides, a suitable band gap $(<3.2 \mathrm{eV})$ and structure of the photocatalysts (heterojunction, $\mathrm{p}-\mathrm{n}$ junction or phase junction), surface reactivity (doped cocatalysts), particle size and distribution of cocatalysts are also key factors for a photocatalytic reaction [9].

Recently, conjugated polymer nanostructures coupled with narrow band gap and unique $\pi$ conjugated electron systems as a new class of photocatalysts have received much attention in various photocatalysis application such as water treatment [10-13] and green $\mathrm{H}_{2}$ production. [14, 15]. However, the photocatalytic efficiency of pristine conjugated polymers is very low due to their rapid charge carrier recombination and sluggish reaction kinetics. A promising way to increase the photocatalytic property of conjugated polymer-based photocatalysts is their combination with semiconductors such as poly(benzothiadiazole) (BBT) [16], poly(3-hexylthiophene) (P3HT) [17], or polypyrrole (PPy) [18] 
modification with titania. Titania composites with conjugated polymers present in general high absorption efficiency in the visible region, less electron-hole recombination, high charge carrier mobility, good stability and excellent biocompatibility. In addition, introducing cocatalysts in conjugated-titania heterostructures can remarkably enhance the photocatalytic efficiency due to the prolonged life time of the charge carriers and increased active sites. Although some conjugated polymer-semiconductor-based ternary structure nanocomposites have successfully constructed such as $\mathrm{Pt} @ \mathrm{TiO}_{2} / \mathrm{g}-\mathrm{C}_{3} \mathrm{~N}_{4}$ [19], $\mathrm{CdS} / \mathrm{Cu}_{7} \mathrm{~S}_{4} / \mathrm{g}-\mathrm{C}_{3} \mathrm{~N}_{4}$ [20], $\mathrm{Au} / \mathrm{TiO}_{2}(\mathrm{P} 25)-\mathrm{gC}_{3} \mathrm{~N}_{4}$ [21], little attention has been paid to considering the multiple electron transfer pathways. Indeed, the multiple electron-transfer pathways are very important for the charge carrier separation and hot electron transfer and accumulation by manipulating deposition cocatalysts on different catalysts in a ternary system [22].

Based on the above considerations, here we successfully fabricated for the first time the ternary hybrid $\mathrm{PPy}-\mathrm{TiO}_{2}$ nanocomposites with small Pt nanoparticles $(2 \mathrm{~nm})$ induced by radiolysis, and we controlled the deposition site on $\mathrm{PPy}, \mathrm{TiO}_{2}$ or on both $\mathrm{PPy}-\mathrm{TiO}_{2}$ (noted respectively (Pt-PPy)-TiO2, $\left(\mathrm{Pt}-\mathrm{TiO}_{2}\right)-\mathrm{PPy}$ and Pt-(PPy-TiO 2$\left.)\right)$. The photocatalytic performance of the different Pt-modified PPy$\mathrm{TiO}_{2}$ composites for hydrogen production under both ultraviolet and visible light irradiation were investigated. The results indicate that $\mathrm{Pt}-\left(\mathrm{PPy}-\mathrm{TiO}_{2}\right)$ structures exhibit significantly enhanced photocatalytic hydrogen production due to more efficient electron separation and transfer compared with (Pt-PPy)-TiO 2 and $\left(\mathrm{Pt}-\mathrm{TiO}_{2}\right)-\mathrm{PPy}$. Our work provides a promising method for the design of ternary nanostructures of metal-semiconductor-conjugated polymer hybrids with high photocatalytic activity for production of solar fuels.

\section{Experimental Section}

\subsection{Materials Preparation}

PPy nanostructures were synthesized by chemical polymerization according to our previous work. In brief, hexagonal mesophases used as soft template were made of a mixture of $\mathrm{NaCl}(0.2 \mathrm{M})$, SDS 
(sodium dodecyl sulfate, $0.8 \mathrm{~g}$ ), cyclohexane as oil phase $(6 \mathrm{~mL})$ and surfactant (n-pentanol, $400 \mu \mathrm{L}$ ). $\mathrm{FeCl}_{3}$ used as oxidant $(0.1 \mathrm{M})$ was added into the mixture, which was vortexed. PPy nanostructures were obtained by oxidation of Py by $\mathrm{Fe}^{3+}$ in the mesophases for $2 \mathrm{~h}$. The mesophase was then destabilized by adding ethanol. Finally, the PPy nanostructures powder was collected by centrifugation, washing and drying [11].

$\mathrm{TiO}_{2} \mathrm{P} 25$ was purchased from Evonik Industries AG (surface area $50 \mathrm{~m}^{2} \mathrm{~g}^{-1}$ ). The $\mathrm{PPy} / \mathrm{TiO}_{2}$ composite was obtained by putting PPy and $\mathrm{TiO}_{2}$ in contact under ultrasounds (30 min) in ethanol suspension. Different $\mathrm{PPy} / \mathrm{TiO}_{2}$ mass ratio were obtained. For the photocatalytic tests the optimized mass ratio between $\mathrm{PPy}$ and $\mathrm{TiO}_{2}$ was found to be $1 / 4$.

Radiolysis is a powerful technique to synthesize metal nanoparticles (NPs) of controlled sizes and shapes [23]. Pt NPs were synthesized by radiolysis (using a panoramic ${ }^{60} \mathrm{Co} \gamma$ source) at a dose rate of $4 \mathrm{kGy} \mathrm{h}^{-1}$. The metal salts or complexes (here $\mathrm{Pt}^{\mathrm{II}}$ (acac)2 purchased from Aldrich) are reduced by solvated electrons and alcohol radicals induced by solvent radiolysis [14].

In the following preparation of samples process, the samples are using theoretical loading rate of $\mathrm{Pt}(1 \mathrm{wt} \%)$. The preparation route of (Pt-PPy)- $\mathrm{TiO}_{2}$ is the following: Firstly, the PPy nanostructures $(20$ $\mathrm{mg})$ were added to an ethanolic solution $(25 \mathrm{~mL})$ containing platinum acetylacetonate $\left(5 \times 10^{-5} \mathrm{M}\right)$. The tube containing the dispersion was closed with a septum, degassed with $\mathrm{N}_{2}$, and then irradiated with $\gamma$-rays $\left({ }^{60} \mathrm{Co} \gamma\right.$ source). After $30 \mathrm{~min}$ irradiation at a dose rate of $4 \mathrm{kGy} \mathrm{h}{ }^{-1}$, the Pt-PPy powder was collected after centrifugation, it was then rinsed with water and ethanol and dried. In a second step, the Pt-PPy composite $(20 \mathrm{mg})$ was mixed with $\mathrm{TiO}_{2}(80 \mathrm{mg})$ in $25 \mathrm{~mL}$ of ethanol under sonication. Finally, the (Pt-PPy)- $\mathrm{TiO}_{2}$ was dried in the oven at $60{ }^{\circ} \mathrm{C}$ for overnight (Figure 1a).

Synthesis of $\left(\mathrm{Pt}-\mathrm{TiO}_{2}\right)-\mathrm{PPy}$. The synthesis procedure of $\left(\mathrm{Pt}-\mathrm{TiO}_{2}\right)-\mathrm{PPy}$ was summarized in Figure 1b. The preparation route is similar to that of (Pt-PPy)-TiO 2 . The only difference is that, in the first step, $\mathrm{TiO}_{2}(80 \mathrm{mg})$ was dispersed into $25 \mathrm{~mL}$ of an ethanol solution containing the $\mathrm{Pt}^{\mathrm{II}}$ precursor $\left(2 \times 10^{-}\right.$ $\left.{ }^{4} \mathrm{M}\right)$. The dispersion was irradiated under $\mathrm{N}_{2}$ atmosphere. The following steps were the same like the 
above mentioned.

Synthesis of Pt-(PPy-TiO 2$)$. PPy $(20 \mathrm{mg})$ were mixed with $\mathrm{TiO}_{2}(80 \mathrm{mg})$ in an ethanol solution $(25 \mathrm{~mL})$ containing platinum acetylacetonate $\left(2.5 \times 10^{-4} \mathrm{M}\right)$. Then the mixture was sonicated for $10 \mathrm{~min}$ to disperse the aggregated nanoparticles and then degassed with $\mathrm{N}_{2}$. The samples were exposed to $\gamma$ rays for 30 min (Figure. 1c).

Samples with different loading rates of $\mathrm{Pt}$ on $\mathrm{PPy}-\mathrm{TiO}_{2}$ were also synthesized labeled as $\mathrm{x} \% \mathrm{Pt}-$ $\left(\mathrm{PPy}-\mathrm{TiO}_{2}\right)$.

(a)
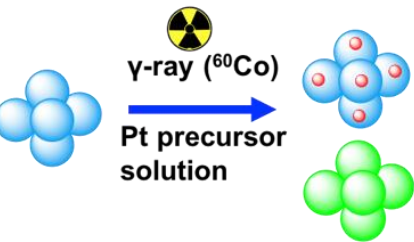

\section{Sonication}

Ethanol solution

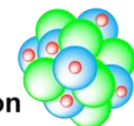

(Pt-PPy)-TiO

(b)
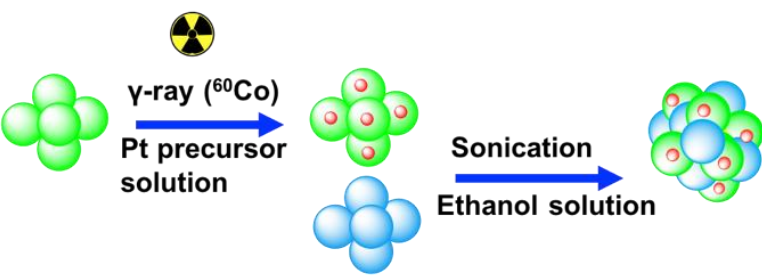

$\left(\mathrm{Pt}_{\mathrm{TiO}}\right)$-PPy

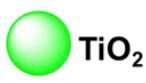

(c)
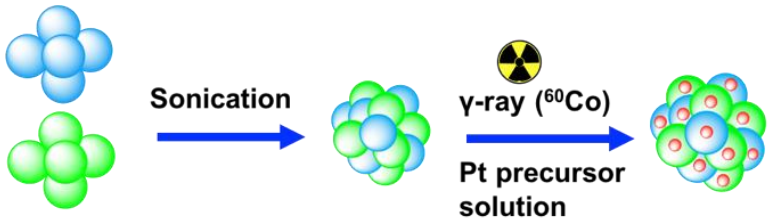

Pt-(PPy-TiO $)$

Figure 1. Schemes of modification of $\mathrm{TiO}_{2}-\mathrm{PPy}$ with Pt cocatalyst deposited on different sites:

$$
\text { on (a) PPy, (b) } \mathrm{TiO}_{2} \text {, and (c) } \mathrm{PPy}-\mathrm{TiO}_{2} \text {. }
$$

\subsection{Characterizations}

Transmission electron microscopy (TEM) (JEOL JEM 2010 UHR operating at $200 \mathrm{kV}$ ) was used to observe the morphology and the structures of nanomaterials.

The UV-vis absorption spectra of the samples were recorded with a Cary 5000 Series, Agilent 
Technologies.

Time-resolved microwave conductivity (TRMC) technique was applied to investigate the lifetime of charge carrier of photocatalysts under different excitation wavelengths. A pulsed light source (Nd: YAG laser) equipped with an optical parametric oscillator (OPO; EKSPLA, NT342B) was used to excite the samples and a Gunn diode $(30 \mathrm{GHz})$ was used to generate microwaves. The principle of TRMC was described in supporting information [24-26].

X-ray photoelectron spectroscopy (XPS) studies were carried out on an Alpha X-ray Spectrometer with monochromatic $\mathrm{Al} / \mathrm{K} \alpha$ under ultrahigh vacuum. C 1s peak $(284.6 \mathrm{eV})$ was used as reference.

The electrochemical measurements were performed in Origalys workstation with a threeelectrode system (the prepared sample electrode, counter electrode of Pt foil and a $\mathrm{Ag} / \mathrm{AgCl}$ electrode as the reference). The working electrodes were prepared by dispersing the samples $(3 \mathrm{mg})$ in ethanol $(3 \mathrm{~mL})$ on fluorine doped tin oxide (FTO) substrate. The samples were then dried at room temperature. For photocurrent density with time $(i-t)$ curve was recorded at a potential of $-200 \mathrm{~V}$. Electrochemical impedance spectra (EIS) were measured in $0.1 \mathrm{M} \mathrm{Na}_{2} \mathrm{SO}_{4}$ solution with an amplitude of $10 \mathrm{mV}$, Frequency: $0.1 \mathrm{~Hz}-1000 \mathrm{~Hz}$ at $0.2 \mathrm{~V}$.

\subsection{Photocatalytic tests}

The photocatalytic activity of the different samples for hydrogen generation under UV and visible light was evaluated. $20 \mathrm{mg}$ of the photocatalyst were dispersed in water-methanol mixture solution (20 $\mathrm{mL}, \mathrm{V}_{\text {methanol }} / \mathrm{V}_{\text {water }}$ is $1 / 4$ ) under stirring. The suspension was bubbled with $\mathrm{N}_{2}$ to remove oxygen and then illuminated under $300 \mathrm{~W}$ xenon lamp. For the experiments under visible irradiation, a filter cutting at $420 \mathrm{~nm}$ was used. Every $10 \mathrm{~min}$ (for UV light) or $1 \mathrm{~h}$ (for visible light), $0.2 \mathrm{~mL}$ of the gas was taken and injected in the gas chromatograph (GC, Shimadzu GC-14B) instrument to analyze the amount of $\mathrm{H}_{2}$. 


\section{Results and Discussion}

\subsection{Characterizations of photocatalysts}

Figure 2 presents the TEM images of Pt-(PPy-TiO 2$)$, (Pt-TiO 2$)-\mathrm{PPy}, \quad(\mathrm{Pt}-\mathrm{PPy})-\mathrm{TiO}_{2}$ nanocomposite materials. When the $\mathrm{Pt}$ precursor is irradiated in the presence of the $\mathrm{PPy}-\mathrm{TiO}_{2}$ composite, Pt NPs are formed on both $\mathrm{TiO}_{2}$, on the polymer and at the interface, with a preferential deposition on PPy. The TEM images of Pt-(PPy-TiO 2$)$ present small and monodisperse $\mathrm{Pt}$ nanoparticles (black dots, $\sim 2.2 \mathrm{~nm}$, Figure S1) on the surface of the $\mathrm{PPy}_{-} \mathrm{TiO}_{2}$ composite (Figure 2ab). The yellow circled parts show preferential deposition of Pt NPs on PPy nanostructures (NSs).

Figure 2c-d shows TEM images of the samples with Pt NPs synthesized on $\mathrm{TiO}_{2}$ previous to the heterojunction with PPy: 2 nm Pt NPs uniformly dispersed on the $\mathrm{TiO}_{2}$ were observed. In addition, $\mathrm{Pt}$ NPs were found to deposit at the edges of $\mathrm{TiO}_{2}$ by radiolytic reduction [27] and Pt NPs were not observed on PPy. Figure 2e-f present TEM images of the samples with Pt NPs synthesis on PPy NSs previous to the heterojunction with $\mathrm{TiO}_{2}$ : Pt NPs of homogeneous size were well dispersed on PPy, and no Pt NPs were observed on $\mathrm{TiO}_{2}$. 

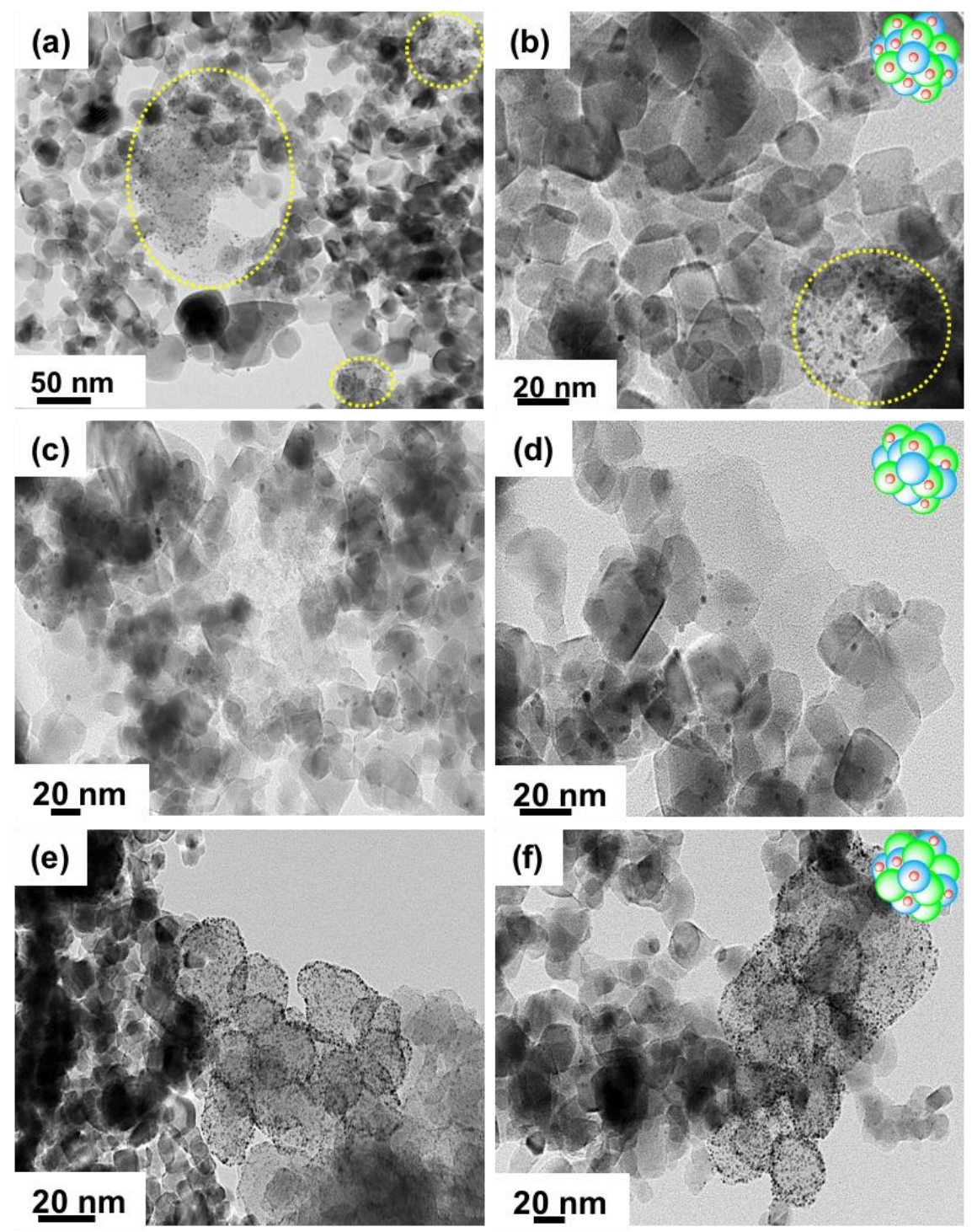

Figure 2. TEM images of (a-b) Pt-(PPy-TiO), (c-d) (Pt-TiO 2$)-\mathrm{PPy}$, (e-f) (Pt-PPy)-TiO2. The mass ratio between $\mathrm{PPy}$ and $\mathrm{TiO}_{2}$ was 1:4 for all the samples.

The UV-vis diffuse reflectance spectra (DRS) of the photocatalysts are shown in Figure 3a. The absorption bands from $200 \mathrm{~nm}$ to $400 \mathrm{~nm}$ are observed owing to the electrons promotion of $\mathrm{TiO}_{2}$ from valence band (VB) to the conduction band (CB) [28]. Compared with bare $\mathrm{TiO}_{2}, \mathrm{Pt}-\mathrm{TiO}_{2}$ show higher absorption under visible light and red shift (to some extent), which characterize the optical properties of Pt NPs on $\mathrm{TiO}_{2}$ [29]. Thanks to the strong absorption of PPy in the visible light region, Pt-(PPy$\mathrm{TiO}_{2}$ ) shows high absorption intensity from $400 \sim 800 \mathrm{~nm}$, indicating a significantly improved 
activation under visible light. Moreover, based on the Kubelka-Munk method, the estimated band gap for $\mathrm{TiO}_{2}, \mathrm{Pt}-\mathrm{TiO}_{2}$ and Pt-(PPy-TiO 2$)$ are $3.20 \mathrm{eV}, 3.06 \mathrm{eV}$ and $2.83 \mathrm{eV}$, respectively (Figure 3b). The narrower band gap of Pt-(PPy- $\left.\mathrm{TiO}_{2}\right)$ is mainly attributed to the heterojunction of titania with PPy nanostructures, which can adsorb more photons to provide more photogenerated charge carriers and improve the photocatalytic property of the photocatalyst. Figure S2 shows the UV-Vis absorption spectra of (Pt-PPy)-TiO 2 , (Pt-TiO 2$)-P P y$ and $\mathrm{Pt}-\left(\mathrm{TiO}_{2}-\mathrm{PPy}\right)$ samples. All these three samples present high absorption in the visible region and the spectra are quite similar. A small difference was observed probably due to the shield of $\mathrm{PPy}$ by $\mathrm{TiO}_{2}$ during the synthesis.

The XRD peaks of the samples correspond to typical anatase and rutile $\mathrm{TiO}_{2}$ patterns, which match with the PDF card number of 99-0008 (anatase) and 99-0090 (rutile) [31] (Figure S3). Because of the small size of Pt NPs, almost no XRD signal of Pt was observed.
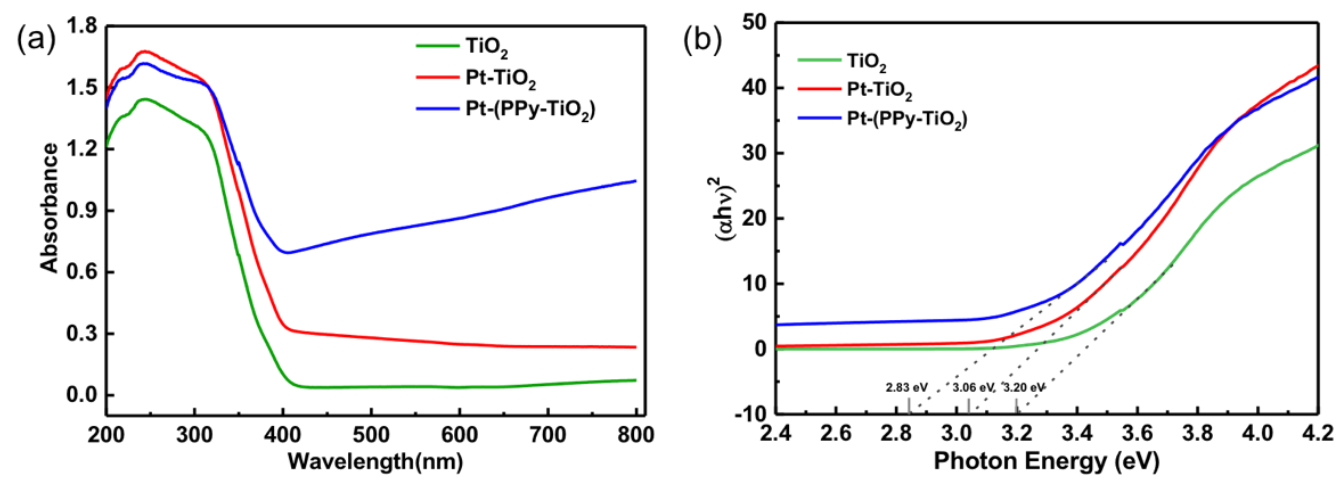

Figure 3. UV-vis absorption spectra (a) and Mott-Schottky plot of the as-prepared samples, (b) (The mass ratio $\mathrm{PPy} / \mathrm{TiO}_{2}$ was 1:4 for all the samples).

The TRMC technique was used to evaluate the dynamics of charge-carriers in $\mathrm{TiO}_{2}$-based composites at different wavelengths. Figure 4a presents the TRMC signals at $360 \mathrm{~nm}$ excitation for pure $\mathrm{TiO}_{2}$, and its platinized form. Pt NPs accelerate the decay at short time range, and does not modify it at long time range [30]. Pt NPs are known to be a sink for electrons, and a sharp fast decay of the signal for the Pt-modified samples is obtained: Pt NPs deposited on $\mathrm{TiO}_{2}$ act as electron scavengers 
decreasing the recombination of charge-carriers, which is beneficial for the photocatalytic activity [20]. Nevertheless, in our previous work, after introducing $\mathrm{PPy}$ in $\mathrm{TiO}_{2}$, the lower signal decay in $\mathrm{PPy}-\mathrm{TiO}_{2}$ than pristine $\mathrm{TiO}_{2}$ was obtained, which may be due to PPy shield effect, fast recombination effect, or fast electron trapping [31]. Interestingly, Figure 4a evidences that the TRMC signal of Pt-(PPy-TiO 2$)$ is not an addition of separate effects of Pt and PPy. A synergetic influence seems to occur. Indeed, the observed signal is quite flat, with a very slow decay. It indicates a real low amount of fast recombination and free $\mathrm{e}^{-}$with high lifetime resulting from good charge-carrier separations. Those effects should be favorable to the activity.

Under visible illumination (at 420 and $450 \mathrm{~nm}$ ), as expected, the TRMC signal is reduced. Pt$\left(\mathrm{PPy}-\mathrm{TiO}_{2}\right)$ shows faster decay at very short range time compared to that of $\mathrm{Pt}-\mathrm{TiO}_{2}$ and $\mathrm{TiO}_{2}$, which indicates more efficient electron trapping and transfer. Moreover, $\mathrm{Pt}-\left(\mathrm{PPy}-\mathrm{TiO}_{2}\right)$ presents a slightly longer lifetime of electrons from the trend of long-rang decay than that of $\mathrm{Pt}_{-} \mathrm{TiO}_{2}$ and $\mathrm{TiO}_{2}($ Figure 4b-c).

The TRMC signals of (Pt-PPy)-TiO 2 , $\left(\mathrm{Pt}-\mathrm{TiO}_{2}\right)-\mathrm{PPy}$ and Pt-(PPy-TiO 2$)$ under UV, at $360 \mathrm{~nm}$, are shown in Figure 4d: Unlike Pt-(PPy-TiO 2$)$, the composites (Pt-PPy)-TiO 2 and (Pt-TiO $)-P P y$ present a fast-global decay, leading to a really low number of charge-carriers after $0.2 \mu \mathrm{s}$. It means that the synergetic effect is only observed on Pt- $\left(\mathrm{PPy}-\mathrm{TiO}_{2}\right)$, which leads to the most efficient electron transfer and the longest life time of electrons. In $\left(\mathrm{Pt}-\mathrm{TiO}_{2}\right)-\mathrm{PPy}$ and $(\mathrm{Pt}-\mathrm{PPy})-\mathrm{TiO}_{2}$ the fast decay is probably be due to high level of recombination. 
(a)

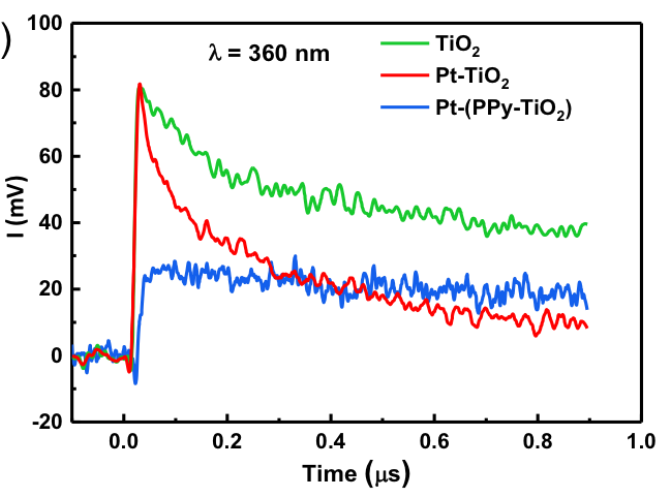

(c)

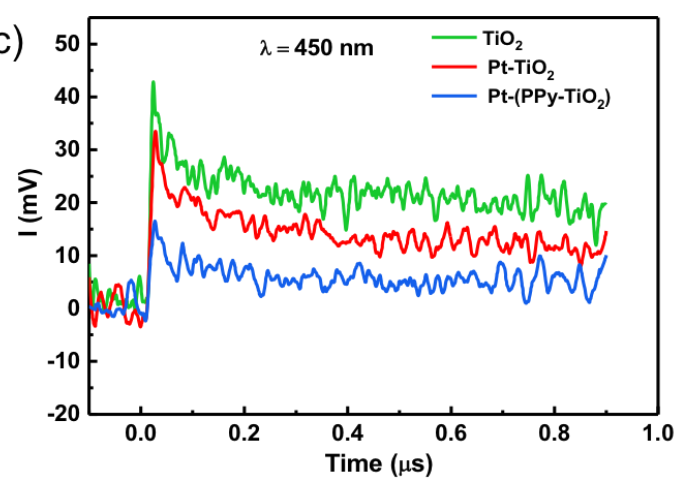

(b)

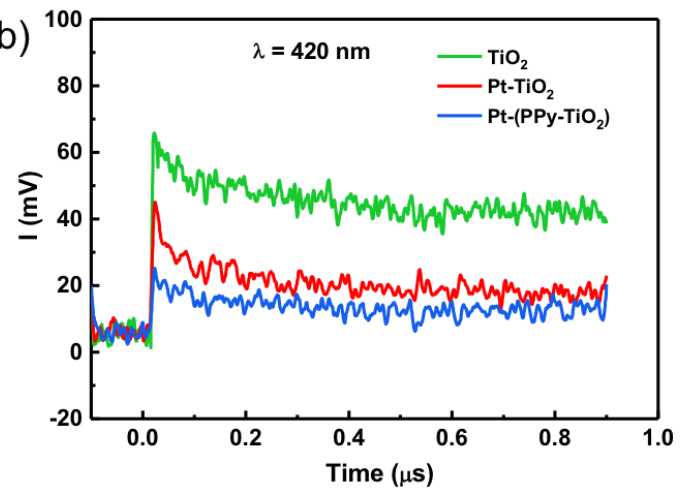

(d)

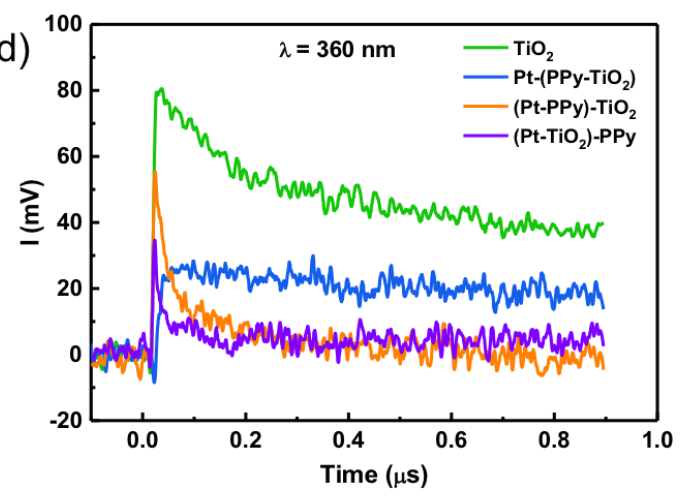

Figure 4. TRMC measurements of Pt-(PPy-TiO $), \mathrm{Pt}_{-} \mathrm{TiO}_{2}$ and $\mathrm{TiO}_{2}$ at $360 \mathrm{~nm}$ (a), $420 \mathrm{~nm}$ (b), 450 $\mathrm{nm}$ (c), respectively. The laser energy of these wavelengths was $1.1,2.3,2.3 \mathrm{~mJ} \cdot \mathrm{cm}^{-2}$. TRMC measurements of (Pt-PPy)-TiO $,\left(\mathrm{Pt}-\mathrm{TiO}_{2}\right)-\mathrm{PPy}, \mathrm{Pt}-\left(\mathrm{PPy}-\mathrm{TiO}_{2}\right)$ and $\mathrm{TiO}_{2}$ at $360 \mathrm{~nm}(\mathbf{d})$. The mass ratio between $\mathrm{PPy}$ and $\mathrm{TiO}_{2}$ was 1:4 for all the samples and the Pt loading is $1 \%$.

The surface composition and chemical states of (Pt-PPy)-TiO 2 , (Pt-TiO 2$)-\mathrm{PPy}$ and Pt-(PPy-TiO 2$)$ were studied by XPS spectroscopy (Figure 5a-d). The full spectrum of Pt-(PPy-TiO 2$)$ contains the signals of C, N, O, and Pt (Figure S4). Pt 4f spectrum of Pt-(PPy-TiO 2$)$ shows that part of Pt in the composite is oxidized. The doublet at $70.78 \mathrm{eV}\left(\mathrm{Pt}_{4 \mathrm{f}_{7 / 2}}\right)$ and $73.98 \mathrm{eV}\left(\mathrm{Pt}_{45} \mathrm{f}_{5 / 2}\right)$ corresponds to metallic Pt which are lower than pure metallic $\mathrm{Pt}\left(\mathrm{Pt}_{4} \mathrm{f}_{7 / 2}=71.2 \mathrm{eV}\right)$ due to the electron transfer happens from $\mathrm{TiO}_{2}$ and PPy to Pt nanoparticles with higher work function [32]. The binding energy at $74.95 \mathrm{eV}(\mathrm{Pt}$ $\left.4 \mathrm{f}_{7 / 2}\right)$ and $76.41 \mathrm{eV}\left(\mathrm{Pt} 4 \mathrm{f}_{5 / 2}\right)$ are corresponding to $\mathrm{PtO}_{2}$, (Figure 5a) [33]. Different valence states of Pt nanoparticles can provide higher active sites and more oxygen defects, which is beneficial for surface chemical adsorption and catalysis [19]. The characteristic peaks of Ti $2 \mathrm{p}_{3 / 2}(458.9 \mathrm{eV})$ and Ti 
2p $\mathrm{p}_{1 / 2}(464.6 \mathrm{eV})$ spectrum of (Pt-PPy)-TiO $2,\left(\mathrm{Pt}-\mathrm{TiO}_{2}\right)-\mathrm{PPy}$ and Pt-(PPy-TiO $)$ show a slight shift $(0.4$ eV) toward higher binding energies compared to pure $\mathrm{TiO}_{2}\left(458.5 \mathrm{eV}\right.$, Ti $\left.2 \mathrm{p}_{3 / 2}\right)$ (Figure 5b). With reference to previous reports on $\mathrm{TiO}_{2}[34,35]$, such higher energy shifts suggest the formation of heterojunction and interactions of the ternary compounds [36]. The C 1s signal for the PPy is located at a binding energy of $284.9 \mathrm{eV}(\mathrm{C}-\mathrm{C}), 286.2 \mathrm{eV}(\mathrm{C}-\mathrm{O})$ and $289.0 \mathrm{eV}(\mathrm{O}-\mathrm{C}=\mathrm{O})$, respectively (Figure 5c). The N 1s high resolution spectra in Figure 5d can be fitted into two peaks, which can be attributed to $\mathrm{N}-\mathrm{C}(399.9 \mathrm{eV})$ and $\mathrm{N}-\mathrm{C}=\mathrm{O}(409.1 \mathrm{eV})[37]$.
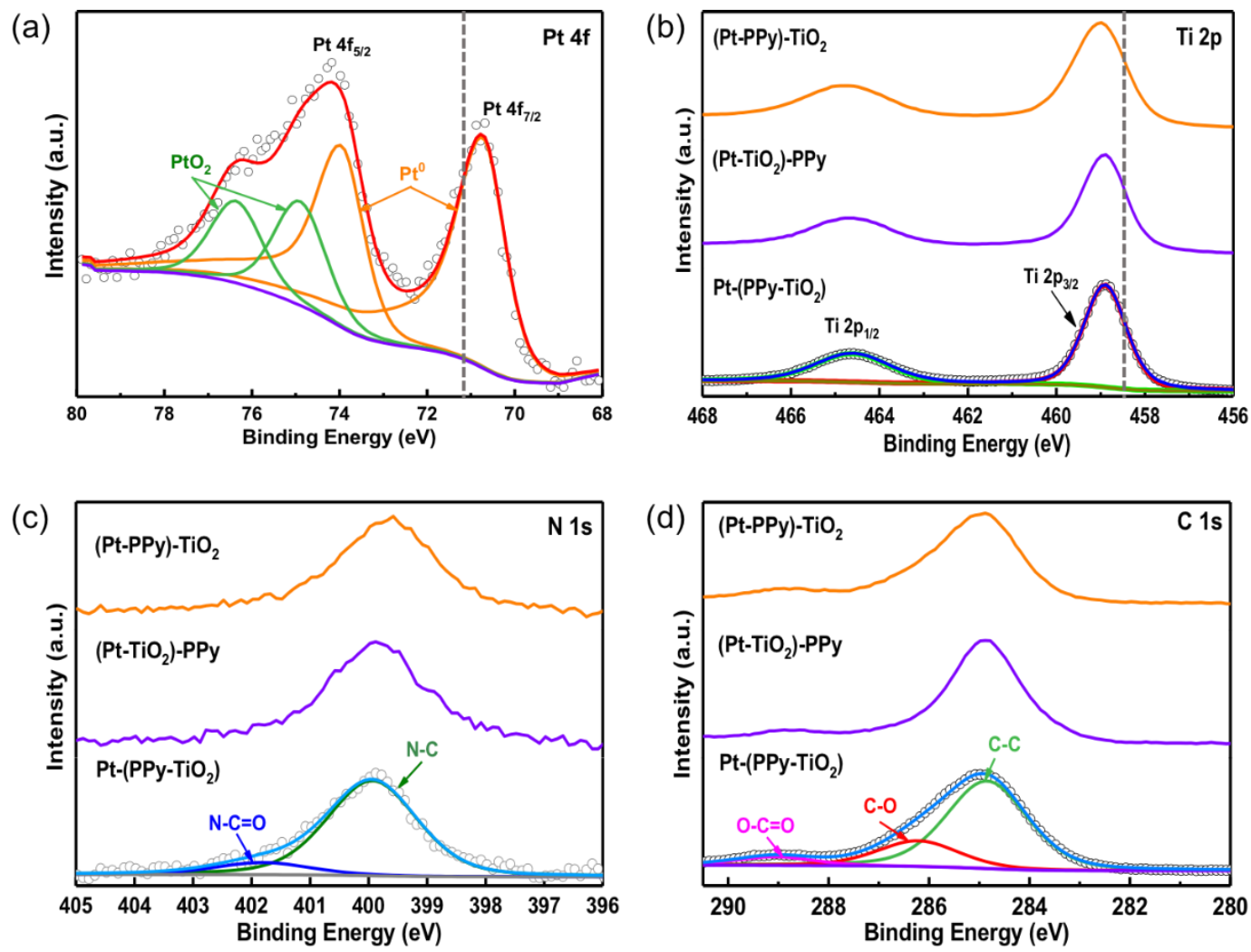

Figure $5 \mathrm{Pt} 4 \mathrm{f}$ XPS spectra of the Pt-(PPy-TiO 2$)$ (a); Ti 2p (b), C 1s (c) and N 1s (d) of the (Pt-PPy)$\mathrm{TiO}_{2}$, (Pt-TiO 2$)-\mathrm{PPy}$ and Pt-(PPy-TiO 2$)$, respectively. The mass ratio between $\mathrm{PPy}$ and $\mathrm{TiO}_{2}$ was 1:4 for all the samples and the Pt loading is $1 \%$.

The transient photocurrent response curves of (Pt-PPy)-TiO $2,\left(\mathrm{Pt}-\mathrm{TiO}_{2}\right)-\mathrm{PPy}$ and Pt- $\left(\mathrm{PPy}-\mathrm{TiO}_{2}\right)$ are shown in Figure 6a. As expected from the TRMC results, the photocurrent intensity of Pt-(PPy- 
$\left.\mathrm{TiO}_{2}\right)$ is 2.7 times higher than that of $(\mathrm{Pt}-\mathrm{PPy})-\mathrm{TiO}_{2}$ and $\left(\mathrm{Pt}-\mathrm{TiO}_{2}\right)-\mathrm{PPy}$ under AM1.5G, which suggests enhanced efficiency of charge transfer and separation of electron-hole pairs in this sample. Additionally, EIS Nyquist plots were used to explore the interface charge transfer resistances of the electrode materials. The smallest semicircle in EIS for Pt-(PPy- $\left.\mathrm{TiO}_{2}\right)$ further demonstrated the highest efficient and fastest interfacial charge transfer ability than $(\mathrm{Pt}-\mathrm{PPy})-\mathrm{TiO}_{2}$ and $\left(\mathrm{Pt}-\mathrm{TiO}_{2}\right)-\mathrm{PPy}($ Figure $6 \mathbf{b})$. These results are consistent with TRMC results and strongly support the excellent photocatalytic activity of Pt-(PPy- $\left.\mathrm{TiO}_{2}\right)$ shown by the following photocatalytic tests.
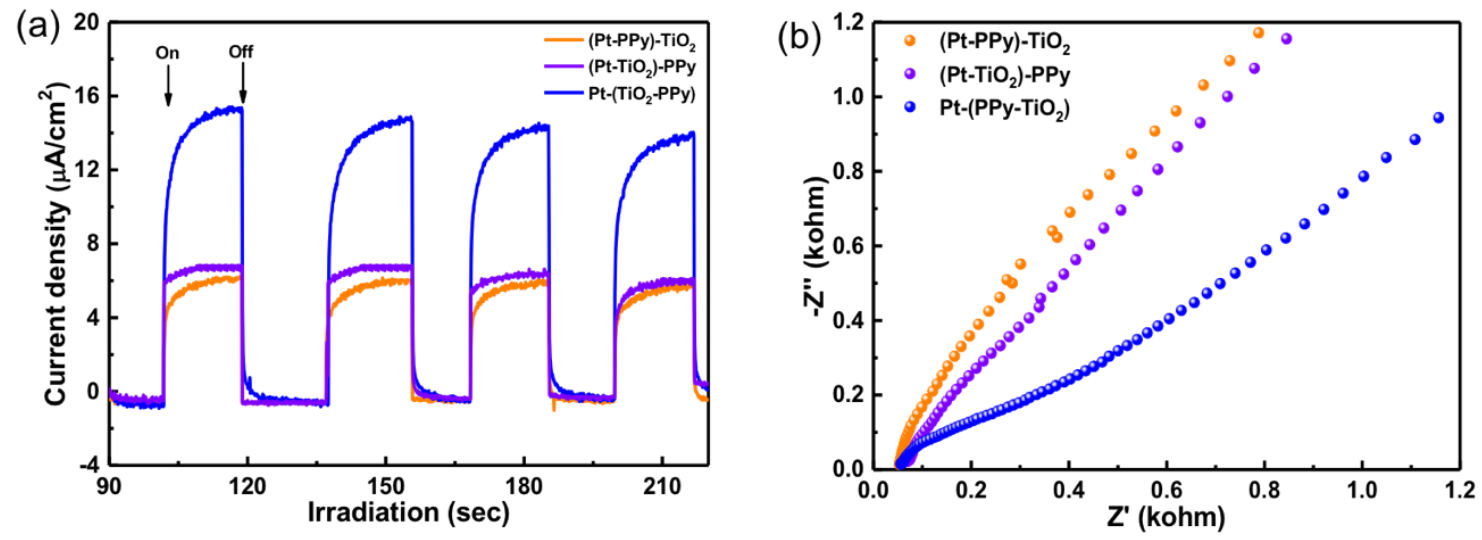

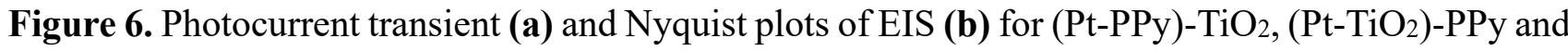
Pt-(PPy-TiO 2$)$ FTO electrodes under UV-vis light irradiation. The mass ratio between $\mathrm{PPy}$ and $\mathrm{TiO}_{2}$ was 1:4 for all the samples and the Pt loading 1\%.

\subsection{Photocatalytic activity for hydrogen generation}

In order to achieve a good photocatalytic activity for hydrogen production, different volume ratios of methanol-water mixture (Figure S5), sacrificial electron donors (Figure S6), and mass ratios of PPy and $\mathrm{TiO}_{2}$ were investigated (Figure 7a). As shown in Figure S5, hydrogen production with 1\%Pt$\left(\mathrm{PPy}-\mathrm{TiO}_{2}\right)$ increased with increasing methanol content until reached to $25 \%$. The photocatalytic activity decreased when the $\mathrm{V}_{\text {methanol }} / \mathrm{V}_{\text {water }}$ was more than $25 \%$, and the very low conversion rate was obtained for the case of $100 \%$ water or pure methanol. F. Besenbacher et al. revealed a proton-transfer 
mechanism that proceeds via an $\mathrm{H}_{3} \mathrm{O}^{+}$-like transition state, which can explain why the methanol-water mixture presents higher photocatalytic activity compared with pure methanol [38]. The effect of different sacrificial reagents (with the same concentration: $0.2 \mathrm{M}$ ) for photocatalytic hydrogen generation was studied (Figure S6). We have found that the highest yield of hydrogen was obtained by the use of methanol owing to the partial production of hydrogen through the methanol conversion $\left(\mathrm{MeOH}+\mathrm{H}_{2} \mathrm{O} \rightarrow \mathrm{CO}_{2}+3 \mathrm{H}_{2}, \Delta \mathrm{G}^{0}=16.1 \mathrm{~kJ} / \mathrm{mol}\right)$ [39]. Furthermore, it is clearly observed that the weight ratio $\left(\mathrm{PPy} / \mathrm{TiO}_{2}\right)$ has a great influence on hydrogen production (Figure 7a). Modification of $\mathrm{TiO}_{2}$ with a small amount of PPy (maximum 25\% in mass) induced an increase in its photoactivity. The photocatalytic activity of $1 \% \mathrm{Pt}-\left(\mathrm{PPy}-\mathrm{TiO}_{2}\right)$ is maximum for the $\mathrm{PPy} / \mathrm{TiO}_{2}$ mass ratio $2: 8$ and decreases drastically with higher ratios. The presence of a large amount of PPy may cover the surface of $\mathrm{TiO}_{2}$ hindering the light absorption and the injection of excited electrons from the LUMO of PPy to the $\mathrm{CB}$ of $\mathrm{TiO}_{2}[40]$.

Photocatalytic hydrogen evolution experiments were conducted in aqueous solution containing $25 \%$ methanol as a hole scavenger. The photocatalyst $\left(1 \% \mathrm{Pt}-\left(\mathrm{PPy}-\mathrm{TiO}_{2}\right)\right)$ is very active for hydrogen production in pure water under UV and visible light. The yield of $\mathrm{H}_{2}$ production reaches $850.0 \mu \mathrm{mol}$ and $27.0 \mu \mathrm{mol}$ after $5 \mathrm{~h}$ under UV and visible light irradiation, respectively (Figure 7b). As shown in Figure 7c-d, $1 \% \mathrm{Pt}-\left(\mathrm{PPy}-\mathrm{TiO}_{2}\right)$ exhibits the highest activity for hydrogen production with $125.1 \mathrm{mmol}$ $\mathrm{h}^{-1} \mathrm{~g}^{-1}$ under UV light and $3.2 \mathrm{mmol} \mathrm{h}^{-1} \mathrm{~g}^{-1}$ under visible light irradiation compared with other loading rates of Pt NPs. The hydrogen evolution rate of $1 \% \mathrm{Pt}-\left(\mathrm{PPy}-\mathrm{TiO}_{2}\right)$ was greatly enhanced with composite materials with appropriate proportion. 
(a)

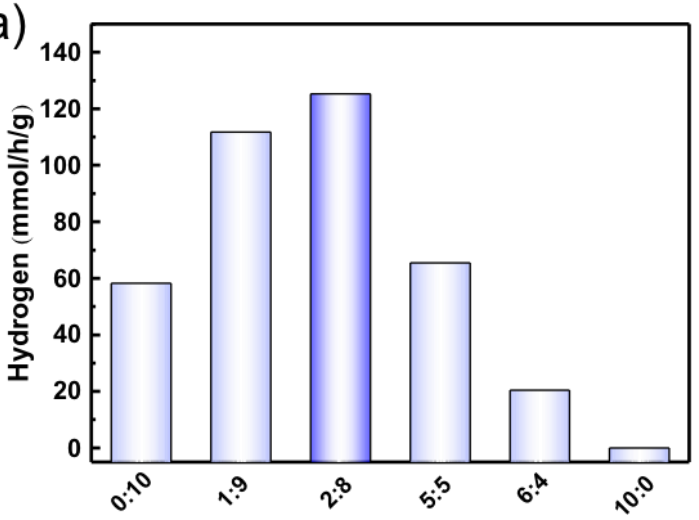

(c)

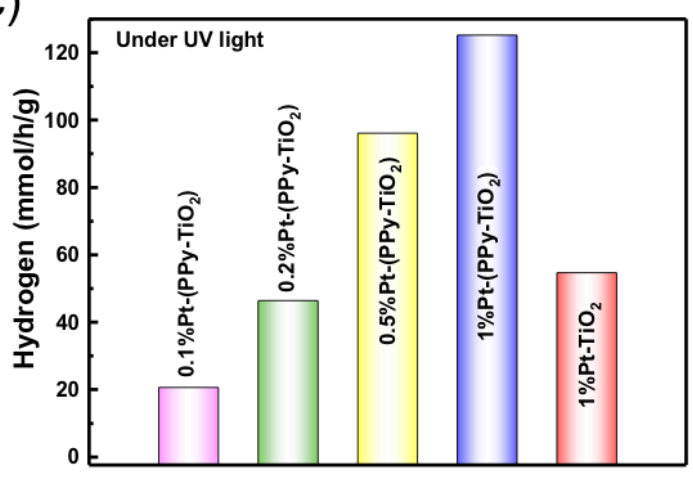

(b)

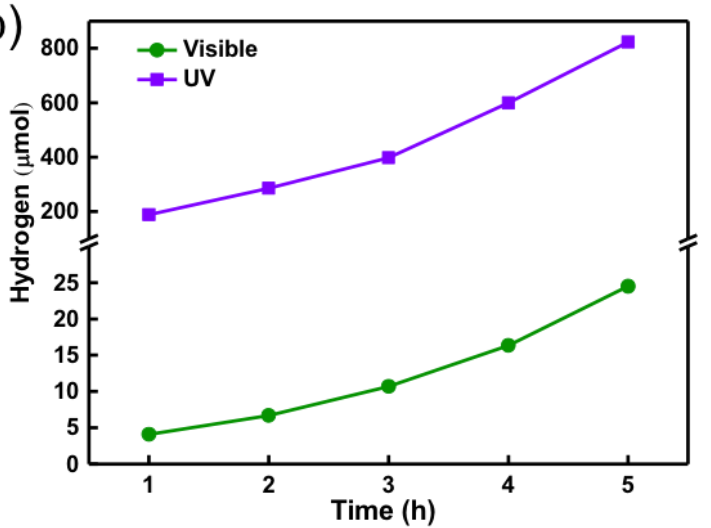

(d)

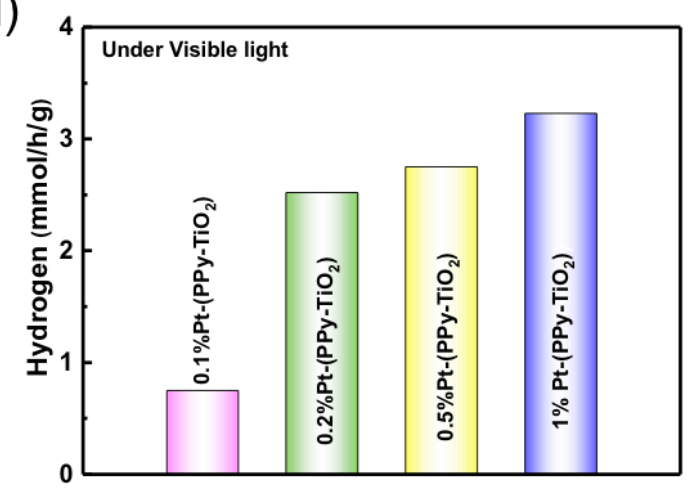

Figure 7. Different mass ratio between $\mathrm{PPy}$ and $\mathrm{TiO}_{2}$ for photocatalytic hydrogen generation (a), Hydrogen production with $1 \% \mathrm{Pt}-\left(\mathrm{PPy}-\mathrm{TiO}_{2}\right)$ in pure water under $\mathrm{UV}$ and visible light $(\mathbf{b})$, hydrogen production with different loading rate of $\mathrm{Pt} \mathrm{NPs}$ on $\mathrm{PPy}-\mathrm{TiO}_{2}$ (with the fixed mass $\mathrm{PPy} / \mathrm{TiO}_{2}$ ratio 20:80) in methanol-water mixture solution (25\% methanol) under both UV light (c), and visible light (d).

$1 \% \mathrm{Pt}-\left(\mathrm{PPy}-\mathrm{TiO}_{2}\right)$ photocatalyst shows a significantly enhanced photocatalytic activity for hydrogen generation $\left(125.1 \mathrm{mmol} \mathrm{h}^{-1} \mathrm{~g}^{-1}\right.$ and $3200 \mu \mathrm{mol} \mathrm{h}^{-1} \mathrm{~g}^{-1}$ under UV and visible light irradiation, respectively) compared with the same loading rate of Pt NPs deposited on PPy $\left(11.8 \mathrm{mmol} \mathrm{h}^{-1} \mathrm{~g}^{-1}\right.$ under UV light and $70.9 \mu \mathrm{mol} \mathrm{h}^{-1} \mathrm{~g}^{-1}$ under visible light, respectively) and $\mathrm{TiO}_{2}\left(24.2 \mathrm{mmol} \mathrm{h}^{-1} \mathrm{~g}^{-1}\right.$ under UV and $454.2 \mu \mathrm{mol} \mathrm{h}^{-1} \mathrm{~g}^{-1}$ under visible light irradiation), respectively (Figure 8a). The higher photocatalytic activity of Pt NPs deposited on $\mathrm{PPy}^{-\mathrm{TiO}_{2}}$ can be ascribed to the routes of effective electron transfer $\left(\mathrm{e}^{-} \mathrm{PPy}(\mathrm{LUMO}) \rightarrow \mathrm{Pt}\right.$ and $\left.\mathrm{e}^{-} \mathrm{PPy}(\mathrm{LUMO}) \rightarrow \mathrm{TiO}_{2(\mathrm{CB})} \rightarrow \mathrm{Pt}\right)$ compared with $(\mathrm{Pt}-\mathrm{PPy})-\mathrm{TiO}_{2}$ and (Pt-TiO) 2 -PPy. Other photocatalysts for hydrogen production have been compared in Table S1. Our 
photocatalyst $\mathrm{Pt}-\left(\mathrm{PPy}-\mathrm{TiO}_{2}\right)$ is very active for hydrogen production under both UV and visible light, and its performance equal or even surpass the literature reports for photocatalysts based on $\mathrm{TiO}_{2}$ or PPy (Table S1)

For practical applications, it is important to check the stability of the photocatalyst. Figure $\mathbf{8 b}$ shows that the photocatalyst $\mathrm{Pt}-\left(\mathrm{PPy}-\mathrm{TiO}_{2}\right)$ is stable with cycling.

(a)

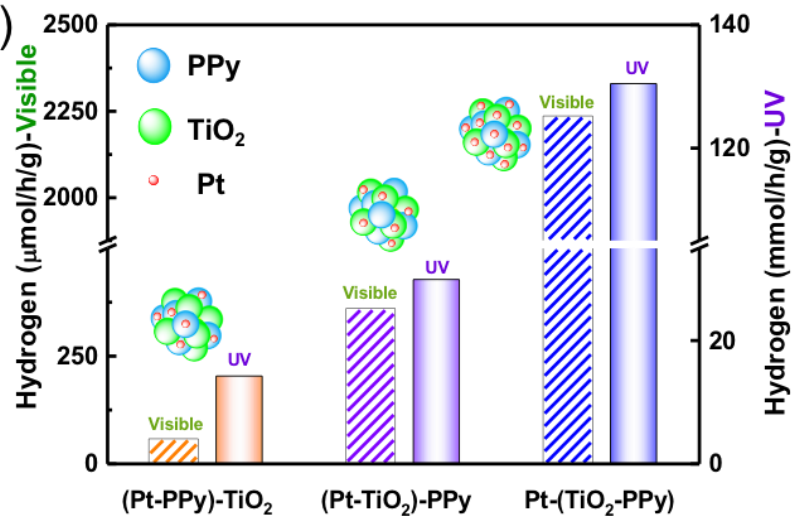

(b)

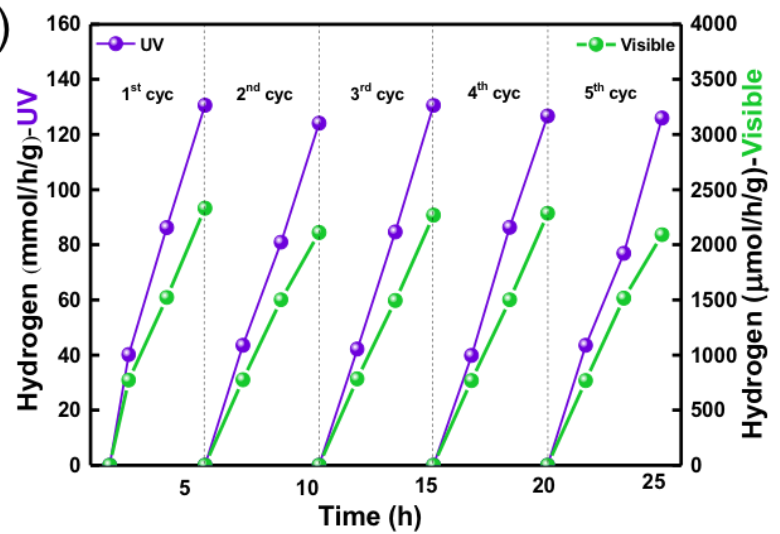

Figure 8. Hydrogen production with (Pt-PPy)-TiO 2 , $\left(\mathrm{Pt}-\mathrm{TiO}_{2}\right)-\mathrm{PPy}$ and $\mathrm{Pt}-\left(\mathrm{PPy}-\mathrm{TiO}_{2}\right)$ in methanolwater mixture solution under UV light and visible irradiation (a); The photocatalytic hydrogen production of Pt-(PPy-TiO 2$)$ with cycling in methanol-water mixture solution (25\% methanol) (b).

\subsection{Electron transfer mechanism of (Pt-PPy)-TiO,$\left(\mathrm{Pt}_{2} \mathrm{TiO}_{2}\right)-\mathrm{PPy}$ and $\mathrm{Pt}-\left(\mathrm{PPy}-\mathrm{TiO}_{2}\right)$}

The migration of electrons under visible-light in the ternary photocatalysts can be explained by the proposed mechanism in Figure 9. Firstly, photocatalytic hydrogen generation involves three main steps: ( ) light absorption, (ii) charge carriers generation and charge transfer to the surface of photocatalysts, and (iii) surface redox reactions [41]. Here, PPy as a photosensitizer was used to absorb the incident light to generate $\mathrm{e}^{-}$and $\mathrm{h}^{+}$. Pt NPs used as a cocatalysts not only serve as sinks for electrons, but also provide proton reductive sites, and centers for $\mathrm{H}^{\cdot}$ radical recombination leading to $\mathrm{H}_{2}$ formation [14]. In addition, thanks to the suitable $\mathrm{CB}$ and VB potential positions of $\mathrm{PPy}$ and $\mathrm{TiO}_{2}$, we could design this very active composite photocatalyst. The energy band structures are described in SI.

As shown in Figure 9a, for the (Pt-PPy)-TiO 2 system, the photogenerated electrons in the LUMO 
of PPy transfer to Pt NPs of PPy surface and also to $\mathrm{TiO}_{2} \mathrm{CB}$. Although for (Pt-PPy)-TiO 2 two electron transfer pathways are proposed, its photocatalytic activity is much lower than $\mathrm{Pt}-\left(\mathrm{PPy}-\mathrm{TiO}_{2}\right)$ because the protons can be reduced into $\mathrm{H}^{\cdot}$ on the surface of $\mathrm{Pt}$ much more efficiently than on bare $\mathrm{TiO}_{2} . \mathrm{Pt}$ NPs help also to form $\mathrm{H}-\mathrm{H}$ bond to lead to $\mathrm{H}_{2}$. In addition, TRMC signals and photocatalytic tests for $\mathrm{H}_{2}$ generation indicate that the electron could transfer from PPy to $\mathrm{TiO}_{2}$, the LUMO of PPy being situated at higher energy position than the $\mathrm{CB}$ of $\mathrm{TiO}_{2}[31]$. The oxidation of an electron donor (such as methanol) with $\mathrm{h}^{+}$happened on the HOMO of PPy $\left(\mathrm{MeOH} \rightarrow 3 \mathrm{H}_{2}+\mathrm{CO}_{2}\right)$.

In $\left(\mathrm{Pt}-\mathrm{TiO}_{2}\right)$-PPy ternary system, PPy is introduced to create electrons from the HOMO to LUMO under visible light illumination (Figure 9b). The photo-induced electrons migration from PPy to the $\mathrm{TiO}_{2} \mathrm{CB}$ due to the position of the PPy LUMO is much more negative than that $\mathrm{TiO}_{2}$, and are eventually injected into the low Fermi level of Pt. As a result, rapid charge separation and slow charge recombination occurred, which results in a good photocatalytic performance. This electron transfer scheme is also illustrated in other ternary systems such as $\mathrm{PPy}-\mathrm{Ag}-\mathrm{TiO}_{2}$ [40], $\mathrm{TiO}_{2} / \mathrm{CuO} / \mathrm{Cu}[42]$, $\mathrm{In}_{2} \mathrm{O}_{3}-\mathrm{TiO}_{2}-\mathrm{Pt}[43]$.

More interestingly, the Pt-( $\left.\mathrm{PPy}-\mathrm{TiO}_{2}\right)$ composite shows the best photocatalytic activity compared with (Pt-PPy)-TiO 2 and $\left(\mathrm{Pt}-\mathrm{TiO}_{2}\right)-\mathrm{PPy}$, because the active $\mathrm{Pt}$ sites coexist in both $\mathrm{PPy}$ and $\mathrm{TiO}_{2}$ (as seen in Figure 2a-b). Figure 9c illustrates two efficient routes of electron transfer. The excited electrons from PPy LUMO migrate to the surface of PPy and $\mathrm{TiO}_{2}$, and then are trapped by Pt deposited on PPy and $\mathrm{TiO}_{2}$ leading to very efficient separation of charge carriers. The most efficient charge carrier separation and transfer in $\mathrm{Pt}-\left(\mathrm{PPy}-\mathrm{TiO}_{2}\right)$ compared with $(\mathrm{Pt}-\mathrm{PPy})-\mathrm{TiO}_{2}$ and $\left(\mathrm{Pt}-\mathrm{TiO}_{2}\right)-\mathrm{PPy}$ were demonstrated by TRMC technique, photoelectrochemical tests and photocatalytic activity. Furthermore, Pt NPs act as a cocatalysts for $\mathrm{H}^{+}$reduction and as a site for $\mathrm{H}^{\cdot}$ recombination. The synergistic effect of the two electron transfer routes and formation of $\mathrm{PPy}_{-} \mathrm{TiO}_{2}$ heterojunction facilitate the photocatalytic reaction process. 
(a)
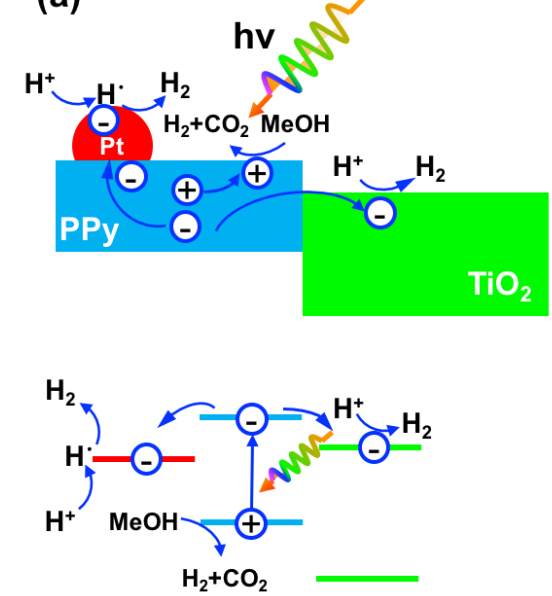

(b)
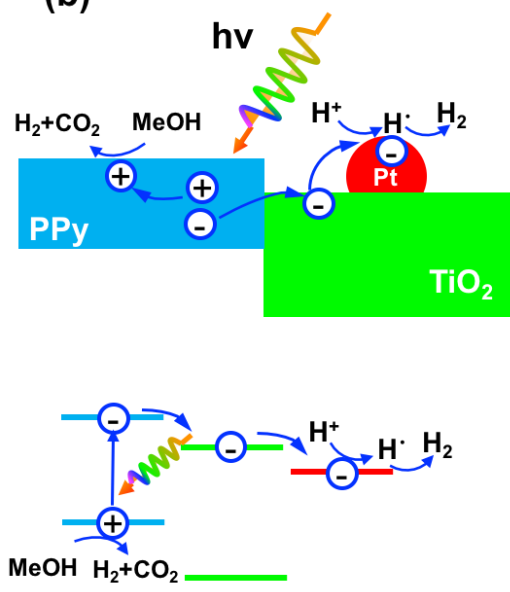

(c)
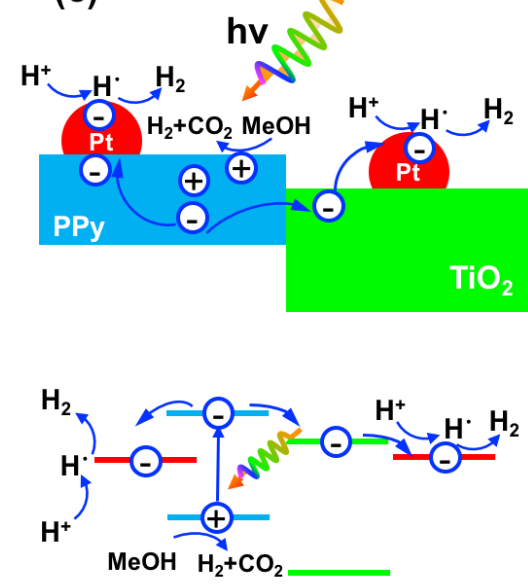

Figure 9. Scheme representation of the electron transfer, migration and hydrogen production mechanism in the hybrid photocatalysts: (a) $(1 \% \mathrm{Pt}-\mathrm{PPy})-\mathrm{TiO}_{2}$; (b) $\left(1 \% \mathrm{Pt}_{-\mathrm{TiO}}\right)-\mathrm{PPy}$; (c) $1 \% \mathrm{Pt}-(\mathrm{PPy}-$ $\left.\mathrm{TiO}_{2}\right)$

\section{Conclusions}

In summary, different ternary nanostructures based on $\mathrm{PPy}^{-\mathrm{TiO}_{2}}$ composites with controlled site modification with Pt nanoparticles were designed. The photocatalytic activity of Pt-(PPy-TiO 2$)$ for hydrogen generation under UV and visible light is very high and drastically surpasses those of (PtPPy)-TiO $2,\left(\mathrm{Pt}-\mathrm{TiO}_{2}\right)-\mathrm{PPy}$ and $\mathrm{Pt}-\mathrm{TiO}_{2}$. With modification of both PPy and $\mathrm{TiO}_{2}$ surface with Pt NPs, an efficient electron transfer from PPy to Pt NPs and through $\mathrm{TiO}_{2}$ to Pt were achieved, which leads to higher charge carriers' separation and accumulation of electrons for the $\mathrm{Pt}-\left(\mathrm{PPy}-\mathrm{TiO}_{2}\right)$ compared with (Pt-PPy)-TiO 2 and $\left(\mathrm{Pt}_{-} \mathrm{TiO}_{2}\right)-\mathrm{PPy}$. More electrons are driven by and to the Pt nanoparticles, which also act as cocatalysts for $\mathrm{H}^{+}$reduction and $\mathrm{H}-\mathrm{H}$ bond formation. The $\mathrm{Pt}-\left(\mathrm{TiO}_{2}-\mathrm{PPy}\right)$ photocatalyst is stable with cycling. This composite may find promising applications in solar fuels generation. This study will open perspectives in the rational design of ternary composites to facilitate charge transfer for high efficient conversion of solar to chemical energy. 


\section{Acknowledgements}

X.Y. gratefully acknowledges the financial support from China Scholarship Council (CSC). This work was supported by the IDEX Paris-Saclay and IRS MOMENTOM. J. Li for his help and M.N. Ghazzal for the access to the photoelectrochemical cell he developed. The authors thank Sylvain Franger for access to XRD characterization and Isabelle Lampre for her help.

\section{Reference}

[1] L. Liu, X. Zhang, L. Yang, L. Ren, D. Wang, J. Ye, Metal nanoparticles induced photocatalysis, National Science Review, 4 (2017) 761-780.

[2] J. Zhang, Z. Yu, Z. Gao, H. Ge, S. Zhao, C. Chen, S. Chen, X. Tong, M. Wang, Z. Zheng, Porous $\mathrm{TiO}_{2}$ nanotubes with spatially separated platinum and $\mathrm{CoO}_{\mathrm{x}}$ cocatalysts produced by atomic layer deposition for photocatalytic hydrogen production, Angewandte Chemie International Edition, 56 (2017) 816-820.

[3] C. Wang, J. Li, E. Paineau, A. Laachachi, C. Colbeau-Justin, H. Remita, M.N. Ghazzal, A sol-gel biotemplating route with cellulose nanocrystals to design a photocatalyst for improving hydrogen generation, Journal of Materials Chemistry A, 8 (2020) 10779-10786.

[4] J. Li, X. Gao, L. Zhu, M.N. Ghazzal, J. Zhang, C.-H. Tung, L.-Z. Wu, Graphdiyne for crucial gas involved catalytic reactions in energy conversion applications, Energy \& Environmental Science, 12 (2020) 1326-1346.

[5] J. Fang, Y. Chen, W. Wang, L. Fang, C. Lu, C. Zhu, J. Kou, Y. Ni, Z. Xu, Highly efficient photocatalytic hydrogen generation of $\mathrm{g}-\mathrm{C}_{3} \mathrm{~N}_{4}-\mathrm{CdS}$ sheets based on plasmon-enhanced triplet-triplet annihilation upconversion, Applied Catalysis B: Environmental, 258 (2019) 117762.

[6] K. Zhu, M. Zhang, X. Feng, L. Qin, S.-Z. Kang, X. Li, A novel copper-bridged graphitic carbon nitride/porphyrin nanocomposite with dramatically enhanced photocatalytic hydrogen generation, Applied Catalysis B: Environmental, 268 (2020) 118434.

[7] Y. Hu, X. Hao, Z. Cui, J. Zhou, S. Chu, Y. Wang, Z. Zou, Enhanced photocarrier separation in conjugated polymer engineered CdS for direct Z-scheme photocatalytic hydrogen evolution, Applied Catalysis B: Environmental, 260 (2020) 118131.

[8] J.B. Joo, R. Dillon, I. Lee, Y. Yin, C.J. Bardeen, F. Zaera, Promotion of atomic hydrogen recombination as an alternative to electron trapping for the role of metals in the photocatalytic production of $\mathrm{H}_{2}$, Proceedings of the National Academy of Sciences, 111 (2014) 7942-7947. 
[9] Q. Zhang, Z. Li, S. Wang, R. Li, X. Zhang, Z. Liang, H. Han, S. Liao, C. Li, Effect of redox cocatalysts location on photocatalytic overall water splitting over cubic $\mathrm{NaTaO}_{3}$ semiconductor crystals exposed with equivalent facets, ACS Catalysis, 6 (2016) 2182-2191.

[10] S. Ghosh, N.A. Kouamé, L. Ramos, S. Remita, A. Dazzi, A. Deniset-Besseau, P. Beaunier, F. Goubard, P.-H. Aubert, H. Remita, Conducting polymer nanostructures for photocatalysis under visible light, Nature Materials, 14 (2015) 505-511.

[11] X. Yuan, D. Floresyona, P.-H. Aubert, T.-T. Bui, S. Remita, S. Ghosh, F. Brisset, F. Goubard, H. Remita, Photocatalytic degradation of organic pollutant with polypyrrole nanostructures under UV and visible light, Applied Catalysis B: Environmental, 242 (2019) 284-292.

[12] D. Floresyona, F. Goubard, P.-H. Aubert, I. Lampre, J. Mathurin, A. Dazzi, S. Ghosh, P. Beaunier, F. Brisset, S. Remita, L. Ramos, R. Hynd, Highly active poly (3-hexylthiophene) nanostructures for photocatalysis under solar light, Applied Catalysis B: Environmental, 209 (2017) 23-32.

[13] S. Ghosh, N.A. Kouame, S. Remita, L. Ramos, F. Goubard, P.-H. Aubert, A. Dazzi, A. DenisetBesseau, H. Remita, Visible-light active conducting polymer nanostructures with superior photocatalytic activity, Scientific Reports, 5 (2015) 1-9.

[14] X. Yuan, D. Dragoe, P. Beaunier, D.B. Uribe, L. Ramos, M.G. Méndez-Medrano, H. Remita, Polypyrrole nanostructures modified with mono-and bimetallic nanoparticles for photocatalytic $\mathrm{H}_{2}$ generation, Journal of Materials Chemistry A, 8 (2020) 268-277.

[15] S. Ghosh, S.R. Keshri, S. Bera, R.N. Basu, Enhanced solar hydrogen generation using $\mathrm{Cu}-\mathrm{Cu}_{2} \mathrm{O}$ integrated polypyrrole nanofibers as heterostructured catalysts, International Journal of Hydrogen Energy, 45 (2020) 6159-6173.

[16] H.-J. Hou, X.-H. Zhang, D.-K. Huang, X. Ding, S.-Y. Wang, X.-L. Yang, S.-Q. Li, Y.-G. Xiang, $\mathrm{H}$. Chen, Conjugated microporous poly (benzothiadiazole)/ $/ \mathrm{TiO}_{2}$ heterojunction for visible-light-driven $\mathrm{H}_{2}$ production and pollutant removal, Applied Catalysis B: Environmental, 203 (2017) 563-571.

[17] D. Wang, J. Zhang, Q. Luo, X. Li, Y. Duan, J. An, Characterization and photocatalytic activity of poly (3-hexylthiophene)-modified $\mathrm{TiO}_{2}$ for degradation of methyl orange under visible light, Journal of Hazardous Materials, 169 (2009) 546-550.

[18] N.M. Dimitrijevic, S. Tepavcevic, Y. Liu, T. Rajh, S.C. Silver, D.M. Tiede, Nanostructured $\mathrm{TiO}_{2}$ /polypyrrole for visible light photocatalysis, The Journal of Physical Chemistry C, 117 (2013) 15540-15544.

[19] Y. Zou, B. Yang, Y. Liu, Y. Ren, J. Ma, X. Zhou, X. Cheng, Y. Deng, Controllable InterfaceInduced Co-Assembly toward Highly Ordered Mesoporous Pt@ $\mathrm{TiO}_{2} / \mathrm{g}-\mathrm{C}_{3} \mathrm{~N}_{4}$ Heterojunctions with Enhanced Photocatalytic Performance, Advanced Functional Materials, 28 (2018) 1806214. 
[20] J. Chu, X. Han, Z. Yu, Y. Du, B. Song, P. Xu, Highly efficient visible-light-driven photocatalytic hydrogen production on $\mathrm{CdS} / \mathrm{Cu}_{7} \mathrm{~S}_{4} / \mathrm{g}-\mathrm{C}_{3} \mathrm{~N}_{4}$ ternary heterostructures, ACS Applied Materials \& Interfaces, 10 (2018) 20404-20411.

[21] P. Jiménez-Calvo, V. Caps, M.N. Ghazzal, C. Colbeau-Justin, V. Keller, $\mathrm{Au} / \mathrm{TiO}_{2}(\mathrm{P} 25)-\mathrm{gC}_{3} \mathrm{~N}_{4}$ composites with low $\mathrm{gC}_{3} \mathrm{~N}_{4}$ content enhance $\mathrm{TiO}_{2}$ sensitization for remarkable $\mathrm{H}_{2}$ production from water under visible-light irradiation, Nano Energy, (2020) 104888.

[22] K. Zhang, J.H. Cha, S.Y. Jeon, K.O. Kirlikovali, M. Ostadhassan, V. Rasouli, O.K. Farha, H.W. Jang, R.S. Varma, M. Shokouhimehr, Pd modified prussian blue frameworks: Multiple electron transfer pathways for improving catalytic activity toward hydrogenation of nitroaromatics, Molecular Catalysis, 492 (2020) 110967.

[23] M. Klein, J. Nadolna, A. Gołąbiewska, P. Mazierski, T. Klimczuk, H. Remita, A. ZaleskaMedynska, The effect of metal cluster deposition route on structure and photocatalytic activity of mono-and bimetallic nanoparticles supported on $\mathrm{TiO}_{2}$ by radiolytic method, Applied Surface Science, 378 (2016) 37-48.

[24] A.L. Luna, D. Dragoe, K. Wang, P. Beaunier, E.K. Kowalska, B. Ohtani, D. Bahena Uribe, M.A. Valenzuela, H. Remita, C. Colbeau-Justin, Photocatalytic Hydrogen Evolution Using Ni-Pd/TiO2: Correlation of Light Absorption, Charge-Carrier Dynamics and Quantum Efficiency, The Journal of Physical Chemistry C, 121 (2017) 14302-14311.

[25] A.L. Luna, E. Novoseltceva, E. Louarn, P. Beaunier, E. Kowalska, B. Ohtani, M.A. Valenzuela, H. Remita, C. Colbeau-Justin, Synergetic effect of Ni and Au nanoparticles synthesized on titania particles for efficient photocatalytic hydrogen production, Applied Catalysis B: Environmental, 191 (2016) 18-28.

[26] M. Méndez-Medrano, E. Kowalska, A. Lehoux, A. Herissan, B. Ohtani, S. Rau, C. Colbeau-Justin, J. Rodríguez-López, H. Remita, Surface Modification of $\mathrm{TiO}_{2}$ with $\mathrm{Au}$ Nanoclusters for Efficient Water Treatment and Hydrogen Generation under Visible Light, The Journal of Physical Chemistry C, 120 (2016) 25010-25022.

[27] N. Roy, K.T. Leung, D. Pradhan, Nitrogen doped reduced graphene oxide based $\mathrm{Pt}-\mathrm{TiO}_{2}$ nanocomposites for enhanced hydrogen evolution, The Journal of Physical Chemistry C, 119 (2015) 19117-19125.

[28] X. Li, P. Wang, B. Huang, X. Qin, X. Zhang, Q. Zhang, X. Zhu, Y. Dai, Precisely locate PdPolypyrrole on $\mathrm{TiO}_{2}$ for enhanced hydrogen production, International Journal of Hydrogen Energy, 42 (2017) 25195-25202.

[29] E. Kowalska, H. Remita, C. Colbeau-Justin, J. Hupka, J. Belloni, Modification of titanium dioxide with platinum ions and clusters: application in photocatalysis, The Journal of Physical Chemistry C, 
$112(2008)$ 1124-1131.

[30] C.A. Emilio, M.I. Litter, M. Kunst, M. Bouchard, C. Colbeau-Justin, Phenol photodegradation on platinized- $\mathrm{TiO}_{2}$ photocatalysts related to charge-carrier dynamics, Langmuir, 22 (2006) 3606-3613.

[31] X. Yuan, M.P. Kobylanski, Z. Cui, J. Li, P. Beaunier, D. Dragoe, C. Colbeau-Justin, A. ZaleskaMedynska, H. Remita, Highly Active Composite $\mathrm{TiO}_{2}$-Polypyrrole Nanostructures for Water and Air Depollution Under Visible Light Irradiation, Journal of Environmental Chemical Engineering, 8 (2020) 104178.

[32] Y. Wang, X. Shang, J. Shen, Z. Zhang, D. Wang, J. Lin, J.C. Wu, X. Fu, X. Wang, C. Li, Direct and indirect Z-scheme heterostructure-coupled photosystem enabling cooperation of $\mathrm{CO}_{2}$ reduction and $\mathrm{H}_{2} \mathrm{O}$ oxidation, Nature Communications, 11 (2020) 1-11.

[33] L.K. Ono, J.R. Croy, H. Heinrich, B. Roldan Cuenya, Oxygen chemisorption, formation, and thermal stability of Pt oxides on Pt nanoparticles supported on $\mathrm{SiO}_{2} / \mathrm{Si}(001)$ : size effects, The Journal of Physical Chemistry C, 115 (2011) 16856-16866.

[34] U. Diebold, T. Madey, $\mathrm{TiO}_{2}$ by XPS, Surface Science Spectra, 4 (1996) 227-231.

[35] P. Stefanov, M. Shipochka, P. Stefchev, Z. Raicheva, V. Lazarova, L. Spassov, XPS characterization of $\mathrm{TiO}_{2}$ layers deposited on quartz plates, Journal of Physics: Conference Series, IOP Publishing, 2008, pp. 012039.

[36] J. Yan, H. Wu, H. Chen, Y. Zhang, F. Zhang, S.F. Liu, Fabrication of $\mathrm{TiO}_{2} / \mathrm{C}_{3} \mathrm{~N}_{4}$ heterostructure for enhanced photocatalytic Z-scheme overall water splitting, Applied Catalysis B: Environmental, 191 (2016) 130-137.

[37] J. Cao, Y. Wang, J. Chen, X. Li, F.C. Walsh, J.-H. Ouyang, D. Jia, Y. Zhou, Three-dimensional graphene oxide/polypyrrole composite electrodes fabricated by one-step electrodeposition for high performance supercapacitors, Journal of Materials Chemistry A, 3 (2015) 14445-14457.

[38] L.R. Merte, G. Peng, R. Bechstein, F. Rieboldt, C.A. Farberow, L.C. Grabow, W. Kudernatsch, S. Wendt, E. Lægsgaard, M. Mavrikakis, F. Besenbacher, Water-mediated proton hopping on an iron oxide surface, Science, 336 (2012) 889-893.

[39] A. Galińska, J. Walendziewski, Photocatalytic water splitting over $\mathrm{Pt}-\mathrm{TiO}_{2}$ in the presence of sacrificial reagents, Energy \& Fuels, 19 (2005) 1143-1147.

[40] Y. Yang, J. Wen, J. Wei, R. Xiong, J. Shi, C. Pan, Polypyrrole-decorated Ag-TiO2 nanofibers exhibiting enhanced photocatalytic activity under visible-light illumination, ACS Applied Materials \& Interfaces, 5 (2013) 6201-6207.

[41] J. Yang, D. Wang, H. Han, C. Li, Roles of cocatalysts in photocatalysis and photoelectrocatalysis, Accounts of Chemical Research, 46 (2013) 1900-1909.

[42] H. Hou, M. Shang, F. Gao, L. Wang, Q. Liu, J. Zheng, Z. Yang, W. Yang, Highly efficient 
photocatalytic hydrogen evolution in ternary hybrid $\mathrm{TiO}_{2} / \mathrm{CuO} / \mathrm{Cu}$ thoroughly mesoporous nanofibers, ACS Applied Materials \& Interfaces, 8 (2016) 20128-20137.

[43] Y.-C. Chen, Y.-C. Pu, Y.-J. Hsu, Interfacial charge carrier dynamics of the three-component $\operatorname{In}_{2} \mathrm{O}_{3}-$ $\mathrm{TiO}_{2}-\mathrm{Pt}$ heterojunction system, The Journal of Physical Chemistry C, 116 (2012) 2967-2975. 